\title{
Emerging principles for health system value improvement programmes
}

\author{
Christopher Moriates, ${ }^{1,2}$ Victoria Valencia ${ }^{1}$
}

\begin{abstract}
1 Internal Medicine and Medical Education, Dell Medical School at The University of Texas at Austin, Austin, Texas, United States

${ }^{2}$ Costs of Care Inc, Boston, Massachusetts, United States
\end{abstract}

\section{Correspondence to} Dr Christopher Moriates, Departments of Internal Medicine and Medical Education, Dell Medical School at The University of Texas at Austin, Austin, TX 78712, USA; cmoriates@austin.utexas.edu

Accepted 11 March 2019 Published Online First 29 March 2019

\section{SLinked}

- http://dx.doi.org/10.1136/ bmjqs-2018-009068

\section{Check for updates}

(c) Author(s) (or their employer(s)) 2019. No commercial re-use. See rights and permissions. Published by BMJ.

To cite: Moriates $C$, Valencia V. BMJ Qual Saf 2019;28:434-437.
Over recent years, hospitals have increasingly focused on improving value: outcomes achieved per dollar spent. ${ }^{1}$ Although prior efforts to address costs and overuse in healthcare date back decades, ${ }^{2}$ the modern movement in hospitals has largely progressed through overlapping stages, focused first on raising awareness and articulating the motivation for addressing costs and healthcare waste in education and care delivery. ${ }^{3-9}$ Some hospital leaders began exploring the effect of simply providing cost transparency to clinicians, with limited results. ${ }^{10}{ }^{11} \mathrm{In}$ concert with the launch of the "Choosing Wisely' campaign in the USA in 2012, hospitalists led projects that largely sought to root out individual areas of overuse and 'things we do for no reason', ushering in a renewed emphasis on utilisation in hospitals. ${ }^{12} 13$ Now, we have begun to see results from health systems that have created organisational value improvement programmes for hospitalised patients to simultaneously address both utilisation and costs, while measuring markers of quality and ensuring favourable patient outcomes. ${ }^{14-16}$

In this issue of BMJ Quality \& Safety, Horwitz and colleagues ${ }^{16}$ describe the impact of a large-scale, hospital valuebased management (VBM) programme at New York University Langone Medical Center (NYU). The institution-wide programme began in April 2014 with significant investment in creating joint clinical and operational leadership, data and cost accounting capabilities, a centralised project support staff, and a shared savings programme. The model focused primarily on projects led by clinicians (with a project manager co-lead) to decrease costs across six main domains: operational efficiency, resource utilisation, supply chain management, revenue cycle, outliers (highest cost patients) and corporate services (administrative and overhead costs). Over the first 3 years of the programme, they chartered 74 total projects, and saw a significant $7.7 \%$ decrease in adjusted variable costs, without measured changes in markers of quality including 30-day same-hospital readmissions and in-hospital mortality.

The authors estimated the total institutional net savings as a whopping \$53.9 million over the 3.75 years since the introduction of the programme in April 2014. This net savings estimate of $\$ 14.3$ million annually accounted for the cost of the programme, which the authors report as $\$ 5.375$ million over the study period. A particular strength of this study is that Horwitz et $a l^{16}$ explicitly calculated adjusted variable costs. Variable costs vary with the level of consumption, as typically occurs with supplies or medications. Reduce antibiotic prescriptions for asymptomatic bacteriuria and the health system realises true savings. ${ }^{17}$ On the other hand, fixed costs for facilities and ancillary services generally persist despite reduced use. Therefore, reductions in lab tests or X-rays, or even length of stay, usually do not translate directly into savings the same way that consumable items such as medications do. Reducing average length of hospital stay does not produce concrete savings until the reductions reach the point that bed closures can occur or staffing reduced. ${ }^{17}$ Many enthusiastic clinicians and managers overlook this important difference between fixed and variable costs when extrapolating their 'cost savings' from projects.

A key challenge in describing a programme of the scale reported by Horwitz and colleagues ${ }^{16}$ is the inability to provide details about the specific projects and programmes, making it challenging 
to understand out of all of the efforts (74 projects!) which actually worked and contributed to these results. This limits how helpful, and generalisable, this account will be to other institutions. However, the real significance of this article lies not so much in helping health systems know exactly which projects and areas to target, as these choices can depend dramatically on idiosyncratic local environments and practices. Rather the significance of this work lies in providing a model or illustration for what an effective centralised programme looks like. This description should inspire health systems by demonstrating what is achievable with some upfront investment. For example, the VBM programme included personnel support for 10 project managers, project leaders and other team members, information technology infrastructure and commitment, and a shared savings model. As health systems become serious about making meaningful changes in overall costs of care, sharing these types of experiences and examples is critical.

\section{EMERGING PRINCIPLES FOR HEALTH SYSTEM VALUE IMPROVEMENT INITIATIVES}

The report of the NYU programme joins the valuedriven outcomes programme from the University of Utah as one of the most well-described, and rigorously evaluated, systematic transformations aimed at value improvement in hospitals in the USA. ${ }^{15} 16$ These programmes are structured similarly to smaller scale models we helped develop at the University of California at San Francisco (UCSF), ${ }^{13} 14$ as well as a faculty-resident project-based programme at the University of Vermont. ${ }^{18}$ We consider this branch of value improvement a closely related but different species from the Lean-based healthcare programmes pioneered by Virginia Mason and the development of care pathways prominently described by Intermountain Healthcare, both of which have also yielded improved outcomes and decreased costs. ${ }^{19}$

Through these early accounts, a number of key elements have emerged for successfully developing system-wide value improvement activities within a health system (table 1). The first is making value improvement an explicit strategic priority through clear leadership endorsement and support. ${ }^{20} 21$ Once improving value is identified as a priority, investments can be made in robust analytical and cost accounting systems, which are required to accurately capture and evaluate both quality and cost data. These capabilities are necessary to visualise potential areas for improvement. We believe these tools and data should be given to front-line clinical leaders, so that they can use them to identify and refine improvement opportunities. Although it is helpful for institutional leadership to set overall strategic priorities, it seems most efficacious when clinical leaders can create their own specific targets, generating buy-in and ensuring the goals are clinically meaningful. ${ }^{15}$ However, empowering

Table 1 Key elements for successfully developing system-wide value improvement activities within health systems

\begin{tabular}{|c|c|c|}
\hline Key element & Explanation & Example(s) \\
\hline $\begin{array}{l}\text { Health system leadership } \\
\text { explicitly identifies value } \\
\text { improvement as a strategic } \\
\text { priority. }\end{array}$ & $\begin{array}{l}\text { Dedication to value improvement is clearly } \\
\text { stated and communicated at multiple levels } \\
\text { of leadership and is integrated within the } \\
\text { organisation's business model. }\end{array}$ & $\begin{array}{l}\text { At the University of Utah, value improvement became the organisation's } \\
\text { business model. }{ }^{20} \text { At NYU, the Dean (who also serves as the CEO of the } \\
\text { health system) convened hospital leaders in } 2013 \text { and recommended a } \\
\text { roadmap to value improvement. }\end{array}$ \\
\hline $\begin{array}{l}\text { Investment in robust cost } \\
\text { and quality analytics and } \\
\text { accounting systems. }\end{array}$ & $\begin{array}{l}\text { Providing access to accurate cost data using } \\
\text { analytical tools that allow users to report, } \\
\text { visualise and investigate cost and outcomes } \\
\text { data. }\end{array}$ & $\begin{array}{l}\text { The University of Utah invested } 8-16 \text { core team members providing } 0.6-1.0 \\
\text { full-time equivalent effort each to build and maintain a cost data model and } \\
\text { visualisation tool. }{ }^{28} \mathrm{NYU} \text { used a customised activity-based costing system. }{ }^{16}\end{array}$ \\
\hline $\begin{array}{l}\text { Engagement of front-line } \\
\text { clinicians in identifying and } \\
\text { refining value improvement } \\
\text { opportunities and priorities. }\end{array}$ & $\begin{array}{l}\text { Involving interprofessional clinicians in } \\
\text { identifying and monitoring priority areas for } \\
\text { improvement including cost and outcome } \\
\text { measures. }\end{array}$ & $\begin{array}{l}\text { UCSF hosted an open platform to collect and curate ideas for value } \\
\text { improvement from anybody on the medical centre staff, allowing for bottom- } \\
\text { up ideas to align with institutional priorities. }{ }^{14} \text { The University of Utah tasked } \\
\text { multidisciplinary improvement teams including clinicians, administrative } \\
\text { leaders and process engineers to define key metrics for quality for their own } \\
\text { domain(s). }{ }^{15}\end{array}$ \\
\hline $\begin{array}{l}\text { A centralised team for } \\
\text { providing project support } \\
\text { and coaching. }\end{array}$ & $\begin{array}{l}\text { Significant resources of interdisciplinary } \\
\text { personnel are prioritised for direct support } \\
\text { of value improvement initiatives, including } \\
\text { data analysts, statisticians, administrators and } \\
\text { improvement experts. }\end{array}$ & $\begin{array}{l}\text { Both the Caring Wisely programme at UCSF and the VBM programme } \\
\text { at NYU dedicated significant resources to a team with diverse expertise } \\
\text { (including programme managers, data scientists, implementation experts } \\
\text { and electronic health record programmers) to provide project support, data } \\
\text { analyses and implementation coaching to clinician-led project teams. }{ }^{1416}\end{array}$ \\
\hline $\begin{array}{l}\text { Regular feedback on } \\
\text { performance at individual } \\
\text { and/or group levels. }\end{array}$ & $\begin{array}{l}\text { Performance data on cost and outcomes data } \\
\text { are presented at regular intervals to both } \\
\text { groups of providers and/or individuals where } \\
\text { appropriate. }\end{array}$ & $\begin{array}{l}\text { UCSF provided individualised 'scorecards' for surgical supply costs to } \\
\text { surgeons at regular intervals, supporting changes in behaviours that resulted } \\
\text { in significant direct cost savings. }\end{array}$ \\
\hline $\begin{array}{l}\text { Dynamic leadership driven } \\
\text { by accountability to } \\
\text { strategic priority. }\end{array}$ & $\begin{array}{l}\text { Leaders at various levels_- programme, } \\
\text { department, practice group-are held } \\
\text { accountable for measurable value improvement } \\
\text { and report this progress to institutional leaders. }\end{array}$ & $\begin{array}{l}\text { At NYU, chairs 'were held accountable to their goals in semi-annual } \\
\text { meetings with the Dean, during which VBM performance was specifically } \\
\text { reviewed and requests for improvement made if necessary'. }{ }^{16}\end{array}$ \\
\hline
\end{tabular}


front-line clinical leaders cannot mean that they are then on their own. A common component of successful programmes thus far has been a skilled centralised team that can provide project support and coaching. These teams can also help provide regular performance feedback to groups. When given achievable benchmark data, physicians are more likely to improve performance. ${ }^{22}$ Lastly, leadership accountability appears critical to realising sustained results. At both NYU and University of Utah, the clinical chairs reported regularly to the Dean/Chief Executive Officer regarding their performance on agreed-upon, value-driven targets. ${ }^{1516}$

In addition to providing the structure for a systemic value improvement programme, addressing these key elements also is likely to contribute to creating an overall high-value care culture within the organisation. $^{2324}$

\section{WHERE HEALTH SYSTEMS NEED TO GO NEXT TO TRULY IMPROVE VALUE}

The work described at UCSF, University of Utah and now at NYU represents a fundamental first step in showing that health systems can indeed improve value. These initial efforts have primarily concentrated on decreasing health system costs of care while maintaining markers of quality. To truly deliver value to patients, however, health systems will need to advance the targets of these programmes towards an emphasis on improving outcomes that matter to patients, including patient-reported outcome and experience measures, but also measures of cost directly relevant to patients, such as ensuring affordability.

Targeting advancement in outcomes that matter to patients may be even more relevant than decreasing costs and waste when tackling value improvement in health systems. Outcomes that matter to patients are often in conflict with the outcomes that matter to health systems and third-party payers, since each faces different risks and costs. Third-party payers, such as private insurance and governmental programmes, typically focus on annual budgets and selected segments of care, and may not even cover the same patient from 1 year to next. Health system 'total costs of care' calculations are almost always confined to individual hospital encounters. This creates a conflict between what matters to patients and what matters to health systems and payers. This conflict is likely directly responsible for the plethora of current measures that tend to focus on process rather than outcome measures, which in turn results in outcomes that often do not really matter to patients. Even many current outcome measures may be too hospital-focused rather than patient-centred. For example, instead of measuring and aiming to decrease hospital length of stay (a measure that is directly relevant to the hospital), it has been proposed that health systems could prioritise home-to-home time, which includes hospital stay along with postacute care stay. ${ }^{25}$ These sorts of changes in outcome measurements would compel clinician-led process redesigns to ensure coordination with postacute care facilities and optimal discharge times for patients. Another potential example focused primarily on improved outcomes, while possibly saving costs, is the Comprehensive Care Physician model, in which physicians focus their practice on patients at increased risk of hospitalisation so that they can provide both inpatient and outpatient care to these high-need patients. ${ }^{26}$

A handful of medical centres have made great strides in decreasing total costs of care. Patients in all health systems will benefit from greater value through their health systems being made more sustainable. However, we have yet to see any evidence that some of these savings are being passed on to patients, for instance through meaningful improvements in affordability of care-a key issue in the USA. It seems unlikely that health system total costs of care savings are ever going to 'trickle down' to the majority of individual patients, except perhaps those without insurance coverage in which the savings from decreased inpatient laboratory tests or other common overuse targets are often minuscule compared with the overall hospital bill. Thus, both efforts to reduce waste and decrease total costs of care for health systems and new measurement methods and interventions to target patient affordability (especially in the USA) are simultaneously needed. Affordability is the 'cost' in the value equation that patients seem to truly care about. ${ }^{27}$ Interventions focused on improved affordability may range from ensuring that the lowest cost medication for an individual patient's insurance coverage is consistently prescribed at the time of discharge to policies that eliminate surprise bills (charges arising when an insured individual inadvertently receives care from an out-of-network provider) and balance billing for patients.

The article from NYU advances the goal posts for health systems about what is possible with committed value improvement efforts. The experience from early leaders in this type of clinician-led, systemically supported change model provides a blueprint for how these goals may now be accomplished at scale.

Funding The authors have not declared a specific grant for this research from any funding agency in the public, commercial or not-for-profit sectors.

Competing interests None declared.

Patient consent for publication Not required.

Provenance and peer review Commissioned; internally peer reviewed.

\section{REFERENCES}

1 Porter ME. What is value in health care? N Engl J Med 2010;363:2477-81.

2 Schroeder SA. Personal reflections on the high cost of American medical care: many causes but few politically sustainable solutions. Arch Intern Med 2011;171:722-7. 
3 Cooke M. Cost consciousness in patient care--what is medical education's responsibility? N Engl J Med 2010;362:1253-5.

4 Berwick DM, Hackbarth AD. Eliminating waste in US health care. JAMA 2012;307.

5 Berwick DM, Nolan TW, Whittington J. The triple aim: care, health, and cost. Health Aff 2008;27:759-69.

6 Moriates C, Soni K, Lai A, et al. The value in the evidence: teaching residents to "choose wisely". JAMA Intern Med 2013;173:308-10.

7 Levinson W, Kallewaard M, Bhatia RS, et al. 'Choosing wisely': a growing international campaign. BMJ Qual Saf 2015;24:167-74.

8 Mafi JN, Parchman M. Low-value care: an intractable global problem with no quick fix. BMJ Qual Saf 2018;27:333-6.

9 McAlister FA, Lin M, Bakal J, et al. Frequency of low-value care in Alberta, Canada: a retrospective cohort study. BMJ Qual Saf 2018;27:340-6.

10 Feldman LS, Shihab HM, Thiemann D, et al. Impact of providing fee data on laboratory test ordering: a controlled clinical trial. JAMA Intern Med 2013;173:903-8.

11 Durand DJ, Feldman LS, Lewin JS, et al. Provider cost transparency alone has no impact on inpatient imaging utilization. J Am Coll Radiol 2013;10:108-13.

12 Feldman LS. Choosing Wisely(®): Things we do for no reason. J Hosp Med 2015;10.

13 Moriates C, Mourad M, Novelero M, et al. Development of a hospital-based program focused on improving healthcare value. J Hosp Med 2014;9:671-7.

14 Gonzales R, Moriates C, Lau C, et al. Caring wisely: a program to support frontline clinicians and staff in improving healthcare delivery and reducing costs. J Hosp Med 2017;12:662-7.

15 Lee VS, Kawamoto K, Hess R, et al. Implementation of a value-driven outcomes program to identify high variability in clinical costs and outcomes and association with reduced cost and improved quality. JAMA 2016;316:1061-72.

16 Chatfield SC, Volpicelli FM, Adler NM, et al. Bending the cost curve: quasi-experimental analysis of a value transformation program at an academic medical center. BMJ Qual Saf 2019;28:449-58.
17 Rauh SS, Wadsworth EB, Weeks WB, et al. The savings illusion--why clinical quality improvement fails to deliver bottom-line results. N Engl J Med 2011;365:e48.

18 Stinnett-Donnelly JM, Stevens PG, Hood VL. Developing a high value care programme from the bottom up: a programme of faculty-resident improvement projects targeting harmful or unnecessary care. BMJ Qual Saf 2016;25:901-8.

19 Kaplan GS. The lean approach to health care: safety, quality, and cost. National Academy of medicine. Available: http:// www.iom.edu/Global/Perspectives/2012/LeanApproach.aspx [Accessed March 4, 2019].

20 Porter ME, Lee TH. From volume to value in health care: the work begins. JAMA 2016;316:1047-8.

21 Moriates C, Wong BM. High-value care programmes from the bottom-up... and the top-down. BMJ Qual Saf 2016;25:821-3.

22 Kiefe CI, Allison JJ, Williams OD, et al. Improving quality improvement using achievable benchmarks for physician feedback: a randomized controlled trial. JAMA 2001;285:2871-9.

23 Gupta R, Moriates C. Swimming upstream: creating a culture of high-value care. Acad Med 2017;92:598-601.

24 Gupta R, Moriates C, Harrison JD, et al. Development of a high-value care culture survey: a modified Delphi process and psychometric evaluation. BMJ Qual Saf 2017;26:475-83.

25 Barnett ML, Grabowski DC, Mehrotra A. Home-to-Home Time - Measuring What Matters to Patients and Payers. N Engl J Med 2017;377:4-6.

26 Meltzer DO, Ruhnke GW. Redesigning care for patients at increased hospitalization risk: the comprehensive care physician model. Health Aff 2014;33:770-7.

27 Emanuel EJ, Glickman A, Johnson D. Measuring the burden of health care costs on us families: the affordability index. JAMA 2017;318:1863-4.

28 Kawamoto K, Martin CJ, Williams K, et al. Value driven outcomes (VDO): a pragmatic, modular, and extensible software framework for understanding and improving health care costs and outcomes. J Am Med Inform Assoc 2015;22:223-35.

29 Zygourakis CC, Valencia V, Moriates C, et al. Association between surgeon Scorecard use and operating room costs. JAMA Surg 2017;152:284-91. 